\title{
Wage Inequality, Technology, and Trade
}

\author{
Joseph Zeira \\ The Hebrew University of Jerusalem and CEPR
}

February 1999*

\begin{abstract}
$\underline{\text { Abstract }}$
The recent widening of the wage gap between skilled and unskilled workers has been attributed either to skill-biased technical progress or to trade liberalization. In this paper both effects are studied in a unified model. Technical progress is modeled as innovations which replace unskilled by skilled workers and trade liberalization is modeled as an increase in the set of tradable goods. We derive two main results. The first is that technical progress increases the wage gap in developed and in less developed countries, while trade liberalization increases the wage gap in developed countries but reduces it in less developed countries. The second result is that while trade liberalization increases trade in all countries, technical progress does not increase trade everywhere. These two results indicate that the recent increase in wage inequality is a combined result of both technical progress and trade liberalization, and cannot be attributed to one factor only.
\end{abstract}

JEL: D3, F16, J31

Keywords: Wage Inequality, Skill-Biased Technical Progress, International Trade.

Mailing Address:

Joseph Zeira

Department of Economics

The Hebrew University of Jerusalem

Mt. Scopus

Jerusalem 91905

Israel

E-mail: mszeira@mscc.huji.ac.il

\footnotetext{
* I am grateful to the Institute of International Economic Studies in Stockholm for its hospitality and to Harry Flam, John Hassler, Omer Moav, Sevi Mora, and Torsten Persson for their helpful comments. Remaining errors are all mine.
} 


\section{Wage Inequality, Technology, and Trade}

\section{Introduction}

In recent decades we have seen a dramatic increase in wage inequality in the US. A similar, though smaller, increase has been observed in other countries. This phenomenon has been documented in many studies, including Davis and Haltwinger (1991), Katz and Murphy (1992), Juhn, Murphy, and Pierce (1993), and Davis (1992). A number of explanations have been offered to this rise in wage inequality. The most popular explanations are skill-biased technical progress on the one hand and the liberalization of international trade on the other hand. ${ }^{1}$ This paper examines the two explanations together within a unified theoretical model, in which technical progress and trade liberalization are two distinct exogenous processes, and in which technology adoption, the amount of trade and wage inequality are endogenous variables. Our main result is that no single explanation can account for the stylized facts of the recent two decades. Hence the rise in wage inequality is a result of both skill-biased technical progress and of trade liberalization.

The paper presents a model in which a final good is produced by many intermediate goods. Technological innovations in this model enable producers to replace unskilled workers by fewer but more skilled workers in production of various intermediate goods. Hence, technical progress reduces one input, i.e. unskilled labor, but increases a second input, i.e. skilled labor. This has two results. The first is that technology adoption increases demand for skilled workers and at the same time also reduces demand for unskilled workers. Hence, technology adoption increases the wage

\footnotetext{
${ }^{1}$ Among the papers that stress the effect of skill-biased technical change are: Bound and Johnson (1992), Katz and Murphy (1992), Berman, Bound, and Machin (1998), and Acemoglu (1998). Among those who stress the role of greater trade openness are Leamer (1993), Wood (1994), and Hanson and Harrison (1995).
} 
ratio between the two types of workers. The second result is, that such innovations are not everywhere adopted by producers, and adoption depends on input prices, namely on the wage ratio between skilled and unskilled workers. ${ }^{2}$ This leads us to an intuitive definition of developed countries vs. less developed ones. Countries that adopt all (or most) new technologies, are called developed, while countries that do not adopt all available technologies, are called less developed. Hence, each country can specialize in a different set of intermediate goods, thus leading to international trade.

International trade is introduced by assuming that some intermediate goods are tradable. A trade liberalization increases the set of these tradable intermediate goods. Technical progress and trade liberalization are independent in the model, as we assume that the tradable goods are distributed uniformly independent of whether they are produced by skilled or unskilled labor. Note, that this independence is only with respect to the exogenous change in trade, due to liberalization, but there is also an endogenous change in trade, which is affected by technical progress. ${ }^{3}$

We find that the results of the model are very different with respect to developed and to less developed countries. In developed countries both technical progress and trade liberalization increase wage inequality. In less developed countries technical progress also increases wage inequality, though by less, but trade liberalization reduces wage inequality. These results imply that recent developments cannot be attributed solely to trade liberalization, since wage inequality has increased not only in developed countries but in less developed countries as well, as shown in Berman, Bound and (1998) and many other studies.

\footnotetext{
${ }^{2}$ This second result appears also in Zeira (1998), where the two inputs are labor and capital.

${ }^{3}$ One could further claim that trade liberalization itself is caused by technical progress in transportation and communication. But since this is only a first attempt to tackle the issue, we assume that the two processes are independent.
} 
The model also enables us to examine the effect of changes not only on wage inequality but on the amounts of trade. We show that technical progress raises the relative amount of trade in one country but reduces it in the other country. This result is at odds with the stylized facts of the recent decades. We have seen a rise in the share of trade in income in all countries, developed as well as less developed. Hence, the recent changes in wage inequality cannot be attributed only to skill-biased technical progress. Hence, we conclude that both factors, technical progress and trade liberalization have played important roles in the widening of wage inequality in developed countries.

The paper is organized as follows. Section 2 presents the model, while section 3 analyzes equilibrium in a closed economy and focuses on technology adoption and wage determination. Section 4 analyzes a two country version of the model with trade. Section 5 examines the effect of technical progress and trade liberalization on wage inequality. Section 6 examines long run implications of the model and section 7 concludes.

\section{The Model}

Consider an economy which produces final output by use of a continuum of intermediate goods $[0,1]$. Production of the final good is described by:

$$
\log y=\int_{0}^{1} \log x_{i} d i
$$

where $y$ is output of final good and $x_{i}$ is input of intermediate good $i$.

Intermediate goods are produced in fixed marginal productivity by unskilled labor or by skilled labor in two different technologies. If an intermediate good $i$ is produced by the unskilled labor technology, production of one unit requires $n_{i}$ units 
of unskilled labor. If $i$ is produced by the skilled labor technology, a production of one unit requires $s_{i}$ units of skilled labor, where: $s_{i}<n_{i}$, namely the skilled labor technology enables reduction of labor input, but it requires a different labor input as well. Denote the relative gain in labor when unskilled workers are replaced by skilled workers by $g(i)$ :

$$
g(i)=\frac{n_{i}}{s_{i}}>1
$$

We assume that the function $g$ is decreasing, namely that the intermediate goods are ordered by decreasing relative labor gain in replacing unskilled by skilled workers.

While the unskilled labor technologies are known from time immemorial, the skilled labor technologies are not known for all intermediate goods and are invented over time. At period $t$ these technologies are known for only some intermediate goods, i.e. for a set $F_{t}$. Technical progress therefore means increasing $F_{t}$, namely creating technologies which enable reducing labor input in production of some intermediate goods, by using skilled instead of unskilled labor. The set $F_{t}$ is called the technology frontier. We do not model inventions in this paper and treat them as exogenous, as we concentrate on technology adoption rather than technology creation. Clearly $\left\{F_{t}\right\}_{t}$ is an increasing sequence of sets, i.e. $F_{t} \supseteq F_{t-1}$ for all $t$. Our measure of technology is the size of $F_{t}$ :

$$
f_{t}=\int_{F_{t}} \mathrm{~d} i
$$

which is an increasing sequence in time. We further specify the technology frontier and assume that each $F_{t}$ is uniformly distributed on $[0,1]$. Note, that this specification means that the innovations are not biased toward any type of 
intermediate goods. ${ }^{4}$ While in this paper we concentrate on increases in $f$, the standard view of skilled biased technical progress is an increase of productivity of skilled workers in all their jobs. This is in this model a reduction of $s_{i}$ for all $i$, namely an increase of $g$. We discuss such a change in Section.

We next turn to describe labor supply of both types of workers. We leave the full specification of individuals and of skill acquisition to a later stage in the analysis. For the meanwhile we only assume that in each period $t$ the amounts of skilled and unskilled workers are predetermined. There is a countinuum of size $S_{t}$ of skilled workers and a continuum of size $N_{t}$ of unskilled workers. We also assume that each worker supplies one unit of labor in one period of time. Hence, the supplies of both types of labor are assumed to be infinitely inelastic in the short-run. ${ }^{5}$

Markets are assumed to be perfectly competitive. We assume that the final good is not traded, but some of the intermediate goods are traded, namely a set $M_{t}$ of intermediate goods, which is uniformly distributed over the interval $[0,1]$. The set $M_{t}$ is determined by type of goods, by geography and by policy. We define a measure for trade openness, which is the size of the set $M_{t}$ :

$$
m_{t}=\int_{M_{t}} \mathrm{~d} i
$$

Trade openness in this economy is therefore characterized by the amount of traded goods. This measure differs from standard ones, such as size of barriers to trade, but is employed here as it fits the model better and it yields similar results to the standard measures. We further assume that there are two countries in the world, A and B. We also assume full capital mobility and that the world interest rate is $r$.

\footnotetext{
${ }^{4}$ The model can be solved also for other specifications of technology frontiers, which are biased toward some intermediate goods. Most of the results are similar. An example can be sent upon request.

${ }^{5}$ See section 7 for long-run analysis.
} 


\section{Equilibrium in a Closed Economy}

We first consider an economy which is closed to international trade, namely the set $M$ of tradable intermediate goods is empty. ${ }^{6}$ Let the price of intermediate good $i$ be $p_{i}$, the wage of skilled workers $w_{s}$, and the wage of unskilled workers $w_{n}$, where the final good serves as a numeraire. Since the economy is closed, all these prices are determined in domestic markets. Before we turn to determination of the various prices and wages, we describe technology choice in production of each intermediate good.

All intermediate goods are produced within the economy. If the skilled technology for an intermediate good $i$ has not been invented yet, i.e. if $i \notin F_{t}$, then clearly the unskilled technology is used. If the skilled technology has already been invented and $i \in F_{t}$, then producers can choose between both technologies. They will adopt the new technology, which uses skilled labor, if and only if

$$
s_{i} w_{s} \leq n_{i} w_{n}
$$

or if:

$$
g(i) \geq \frac{w_{s}}{w_{n}}
$$

Hence, the wage ratio between skilled and unskilled workers determines technology adoption. This variable, which describes wage inequality in the economy, is the main variable in our analysis and is called the wage ratio. It is easy to see that the set of adopted technologies is $[0, d] \cap F$, where:

$$
d=\min \left\{g^{-1}\left(\frac{w_{s}}{w_{n}}\right), 1\right\}
$$

\footnotetext{
${ }^{6}$ From here on we delete time subscripts wherever possible.
} 
Hence, there are two cases. In the first case $d=1$ and all new technologies are adopted. In the second case $d<1$ and not all new technologies are adopted. The first case prevails when $w_{s} / w_{n} \leq g(1)$, and the second one prevails when $w_{s} / w_{n}>g(1)$. We say that the higher is $d$ the more 'developed' the country is. We sometimes call a country that adopts all technologies 'fully developed'.

We next turn to the goods markets to describe price determination. Due to perfect competition in output and input markets, we get the following first order condition:

$$
p_{i}=\frac{\partial y}{\partial x_{i}}=\frac{y}{x_{i}}
$$

Due to perfect competition in input markets and due to constant marginal productivity we get:

$$
p_{i}= \begin{cases}w_{s} s_{i} & \text { if } 0 \leq i \leq d \text { and } i \in F \\ w_{n} n_{i} & \text { otherwise }\end{cases}
$$

In order to describe wage determination we turn to the equilibrium conditions in the two labor markets in the economy, omitting time subscripts as the equilibrium is temporal. Equilibrium in the market for skilled labor is reached when supply equals demand and due to (8) and (9) we get:

$$
S=\int_{[0, d] \cap F} s_{i} x_{i} \mathrm{~d} i=d f \frac{y}{w_{s}} .
$$

Similarly, the equilibrium condition in the market for unskilled labor is:

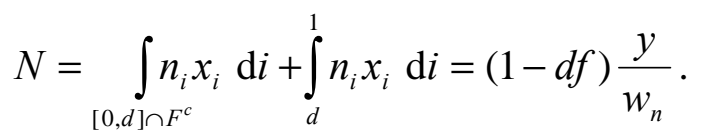

From (10) and (11) we get:

$$
\frac{w_{s}}{w_{n}}=\frac{N}{S} \frac{d f}{1-d f} .
$$


The right hand side of equation (12), which describes the wage ratio and which we denote by $W R$, is an increasing function of $d$. Furthermore, $W R$ depends positively on the state of technology $f$ and on the relative supplies of skilled and unskilled workers.

\section{[Insert Figure 1 here]}

The equilibrium wage ratio and the level of technology adoption $d$ in the closed economy are determined by equations (7) and (12). This is described in Figure 1 at the intersection of the $W R$ curve and the curve which describes $g$. There are two possible equilibria. If the educational system is sufficiently large and there are many skilled workers, as described by point A in Figure 1, all new innovations are adopted and the economy is fully developed. If on the contrary the education system is small and there are few skilled workers and many unskilled workers, the equilibrium is described by point $B$ in Figure 1. In this case some of the new technological innovations, those between $d$ and 1 , are not adopted, and the economy is what we call less developed.

To complete the description of equilibrium we derive the absolute wage levels of skilled and unskilled workers. From the first order condition (8) and from the production function (1) we get:

$$
\int_{0}^{1} \log p_{i} \mathrm{~d} i=0 .
$$

By substituting (9) and the wage ratio (12) in equation (13) we can calculate the wage of skilled workers:

$$
\begin{aligned}
& \log w_{s}=(1-d f) \log \frac{d f}{1-d f}+(1-d f) \log \frac{N}{S}- \\
& -f \int_{0}^{d} \log s_{i} \mathrm{~d} i-(1-f) \int_{0}^{d} \log n_{i} \mathrm{~d} i-\int_{d}^{1} \log n_{i} \mathrm{~d} i
\end{aligned}
$$


and the wage of unskilled workers:

$$
\begin{gathered}
\log w_{n}=-d f \log \frac{d f}{1-d f}-d f \log \frac{N}{S}- \\
-f \int_{0}^{d} \log s_{i} \mathrm{~d} i-(1-f) \int_{0}^{d} \log n_{i} \mathrm{~d} i-\int_{d}^{1} \log n_{i} \mathrm{~d} i .
\end{gathered}
$$

We now turn to analyze the effect of technical progress on equilibrium in the closed economy. An increase in $f$ shifts the $W R$ curve upward and thus raises the wage ratio. Note, that if the economy is fully developed, the effect of an increase in $f$ is larger than in a less developed economy. In a fully developed country the wage ratio rises by the full amount of the increase in $W R$, while it rises by less if the economy is less developed, due to the downward slope of $g$. Note also, that although $d$ decreases or remains unchanged, when $f$ rises, the amount of intermediate goods produced by skilled workers increases, since $d f$ increases as can be seen from (12).

\section{World Trade Equilibrium}

In this section we assume that there are two large economies. One economy $\mathrm{A}$ has a large amount of skilled workers $S_{A}$ and a small amount of unskilled labor $N_{A}$. This economy adopts all technologies up to an intermediate good $d_{A}$, which might also be equal to 1. Economy B on the contrary has a small amount of skilled labor $S_{B}$ and a large amount of unskilled labor $N_{B}$, due to a small educational sector. Hence, it adopts technologies only up to an intermediate good $d_{B}$, where $d_{B}<d_{A}$.

While the intermediate goods in $M$ have the same price across countries, the

final good, skilled and unskilled labor and the intermediate goods in $M^{c}$ have different prices across countries. In order to describe the pattern of international trade between the two countries we show first that wages of skilled workers are lower in country A, while wages of unskilled workers are lower in country B. 
Lemma 1: The wages in the two countries satisfy: $w_{s A} \leq w_{s B}$ and $w_{n A} \geq w_{n B}$ and one of the inequalities is strict.

Proof: Note first, that it is impossible that both inequalities are violated, since then the wage ratio in $\mathrm{A}$ is higher than in $\mathrm{B}$, which contradicts greater technology adoption in A. A similar argument shows that two equalities are impossible.

We next show that if only one inequality is violated, for example if $w_{S A}>w_{s B}$, we reach a contradiction as well. Consider two possible cases for wages of unskilled. If $w_{n B}<w_{n A}$ then country $\mathrm{A}$ is importing all goods from country $\mathrm{B}$, which is impossible. If $w_{n B}=w_{n A}$ the wage ratio in country $\mathrm{A}$ is higher than in country $\mathrm{B}$, which contradicts the assumption. Hence, both wage inequalities hold.

\section{QED.}

From Lemma 1 we conclude that country A is exporting intermediate goods produced by skilled labor, while country B is exporting intermediate goods produced by unskilled labor. If an inequality is strict, the respective country produces all the global consumption of the intermediate goods it exports and there is complete specialization. If wage levels are equal in both countries, there is some domestic consumption of these goods in the importing country. There are therefore three possible cases: full specialization, equality of wages of skilled workers in both countries or equality of wages of unskilled workers in the two countries. We focus our attention on the first two cases, as the third seems to be less realistic, and it adds no new insight.

The international price of an intermediate good exported by country A is therefore: 


$$
p_{i}=w_{s A} s_{i}
$$

while the international price of an intermediate good imported by country A is:

$$
p_{i}=w_{n B} n_{i}
$$

Country A exports intermediate goods in $M$ as long as $w_{s A} s_{i} \leq w_{n B} n_{i}$, namely as long as:

$$
g(i) \geq \frac{w_{s A}}{w_{n B}}
$$

Hence, country A is exporting the set of intermediate goods $M \cap F \cap[0, k]$, where $k$ is determined by:

$$
k=\min \left\{g^{-1}\left(\frac{w_{s A}}{w_{n B}}\right), 1\right\} .
$$

Country B is exporting intermediate goods produced by non-skilled, which includes all traded goods except those exported by A, i.e. $M \backslash M \cap F \cap[0, k]$. The pattern of international trade is graphically described in Figure 2. Note, that due to Lemma $1 k$ is always between $d_{A}$ and $d_{B}$. In the case of full specialization $k$ is strictly between them. If skilled wages in the two countries are equal, then $k=d_{B}$.

\section{[Insert Figure 2 here]}

Before we turn to analyze the two cases we focus on we derive the inputs of intermediate goods in each country from the first order conditions. The input of intermediate good $i$ in country $j$, where $j \in\{\mathrm{A}, \mathrm{B}\}$ is:

$$
x_{i j}=\frac{p_{j} y_{j}}{p_{i j}},
$$

similarly to equation (8).

\section{A. Equilibrium with Full Specialization}


We first analyze the case of full specialization, where skilled wages in A are strictly lower than in B. In this case all the input of traded skilled goods in B is supplied by A. Since global trade must be balanced and we get:

$$
\int_{F \cap M \cap[0, k]} p_{i} x_{i B} \mathrm{~d} i=\int_{M \backslash M \cap F \cap[0, k]} p_{i} x_{i A} \mathrm{~d} i
$$

From this condition and from (20) we can derive the ratio of incomes in the two countries:

$$
\frac{p_{B} y_{B}}{p_{A} y_{A}}=\frac{1-k f}{k f}
$$

Hence, the income ratio depends negatively on $k$.

We next present the four labor market equilibrium conditions. The equilibrium condition for skilled labor in $\mathrm{A}$ is:

$$
\begin{aligned}
& S_{A}=\underset{[0, k] \cap F \cap M}{\int} s_{i}\left(x_{i A}+x_{i B}\right) \mathrm{d} i+\int_{\left[0, d_{A}\right] \cap F \cap M^{c}} s_{i} x_{i A} \mathrm{~d} i= \\
& =\left[k f m\left(p_{A} y_{A}+p_{B} y_{B}\right)+d_{A} f(1-m) p_{A} y_{A}\right] \frac{1}{w_{S A}} .
\end{aligned}
$$

The equilibrium condition in the market for non-skilled labor input in A is:

$$
N_{A}=\int_{\left[0, d_{A}\right] \cap F^{c} \cap M^{c}} s_{i} x_{i A} \mathrm{~d} i+\int_{\left[d_{A}, 1\right] \cap M^{c}} s_{i} x_{i A} \mathrm{~d} i=\left(1-d_{A} f\right)(1-m) \frac{p_{A} y_{A}}{w_{n A}}
$$

Similarly, the equilibrium in the market for skilled labor in B is reached at:

$$
S_{B}=\int_{\left[0, d_{B}\right] \cap M^{c} \cap F} s_{i} x_{i B} \mathrm{~d} i=d_{B} f(1-m) \frac{p_{B} y_{B}}{w_{s B}},
$$

while equilibrium condition for non-skilled labor in B is:

$$
\begin{gathered}
N_{B}=\int_{M \backslash M \cap F \cap[0, k]} n_{i}\left(x_{i B}+x_{i A}\right) \mathrm{d} i+\int_{M^{c} \backslash\left[0, d_{B}\right] \cap F \cap M^{c}} n_{i} x_{i B} \mathrm{~d} i= \\
=\left\{\left[m-k f m+(1-m)\left(1-d_{B} f\right)\right] p_{B} y_{B}+[m-k f m] p_{A} y_{A}\right\} \frac{1}{w_{n B}} .
\end{gathered}
$$


From the labor equilibrium condition and from condition (22) on the income ratio in the two countries we can derive the wage ratios in the two countries. The wage ratio in country $\mathrm{A}$ is:

$$
\frac{w_{s A}}{w_{n A}}=\frac{N_{A}}{S_{A}} \frac{m+d_{A} f(1-m)}{(1-m)\left(1-d_{A} f\right)},
$$

while the wage ratio in country $B$ is:

$$
\frac{w_{s B}}{w_{n B}}=\frac{N_{B}}{S_{B}} \frac{d_{B} f(1-m)}{1-d_{B} f(1-m)} .
$$

Equations (23) and (24) together with the condition on technology adoption (6) determine the equilibrium in each economy, i.e. the degrees of technology adoption and the wage ratio in each country. Note, that the right hand side of equation (23), which we denote by $W R_{A}$, is an increasing function of $d_{A}$ and hence there exists a unique intersection with $g$, which is decreasing in $d_{A}$. This intersection determines both $d_{A}$ and the wage ratio in A, as shown in Figure 3. Similarly, the right hand side of (24), which is denoted $W R_{B}$, is increasing in $d_{B}$ and hence has a unique intersection with $g$, which determines the equilibrium in B.

\section{[Insert Figure 3 here]}

We next turn to determination of equilibrium $k$ and the pattern of international trade. From the labor market conditions and from the income ratio we derive the ratio between skilled wage in the developed economy and non-skilled wage in the less developed economy:

$$
\frac{w_{s A}}{w_{n B}}=\frac{N_{B}}{S_{A}} \frac{m+d_{A} f(1-m)}{1-d_{B} f(1-m)} \frac{k f}{1-k f} .
$$

This condition together with the trade condition (18) determines $k$. Since the right hand side of (25) is an increasing function of $k$ it has a unique intersection with $g$. This intersection determines $k$ and thus the pattern of trade. Note, that to ensure that 
this is a full specialization equilibrium $k$ need to be strictly smaller than $d_{A}$ and strictly larger than $d_{B}$. The conditions for that can be found by a straightforward calculation.

\section{B. Equilibrium without Full Specialization in Skilled Goods}

When the wages of skilled workers are equal in the two countries county B also produces some of the traded skilled goods in $\left[0, d_{B}\right]$. Hence, the world trade equilibrium is:

$$
\int_{F \cap M \cap\left[0, d_{B}\right]} p_{i} e x_{i A} \mathrm{~d} i=\int_{M \backslash M \cap F \cap\left[0, d_{B}\right]} p_{i} x_{i A} \mathrm{~d} i=p_{A} y_{A} m\left(1-d_{B} f\right),
$$

where $e x_{i A}$ is export of $i$ from A.

The equilibrium conditions of the four labor markets are derived in a similar way to that under full specialization. From these conditions and from (26) we calculate the wage ratios in the two countries. It can be shown that the wage ratio in country $\mathrm{A}$ is the same as in full specialization and is given by (23). Hence, the wage ratio $W R_{A}$ and $d_{A}$ are the same in the two cases. The wage ratio in country $\mathrm{B}$ is determined by the following condition:

$$
\frac{w_{s B}}{w_{n B}}=\frac{m+(1-m) d_{A} f}{m+(1-m) d_{A} f+m S_{A} / S_{B}} \frac{d_{B} f}{1-d_{B} f},
$$

and by (6). We have therefore shown that in both cases (and in the third case as well) an equilibrium exists and is unique, and we have fully characterized it.

\section{The Effects of Technical Progress and of Trade Liberalization}

We next examine how technical progress and trade liberalization affect the equilibrium in both countries, the developed and the less developed. We model 
technical progress as increasing $f$, i.e. increasing the set of inventions which enable production by skilled workers. We model trade liberalization by increasing $m$, i.e. increasing the set of traded goods. We first examine the effect of these changes in a full specialization equilibrium and we then turn to an economy without full specialization of skilled goods.

Let us first consider the world in an equilibrium of full specialization. In order to analyze the effect of skill-biased technical change, note, that an increase in $f$ increases $W R_{A}$ and thus shifts upward the $W R_{A}$ curve in figure 3. As a result $d_{A}$ is reduced if smaller than 1 , or stays unchanged if equal to 1 . The wage ratio increases in both cases, and by much more if $d_{A}$ is equal to 1 . Hence, technical progress increases the wage ratio by increasing the demand for skilled workers and reducing demand for unskilled. In the less developed economy the effect of technical progress is similar. An increase in $f$ increases $W R_{B}$ and thus reduces $d_{B}$ and increases the wage ratio in country $\mathrm{B}$ as well. Note, that although the effects are in the same direction, they differ quantitatively. We examine the relative changes in $W R_{A}$ and in $W R_{B}$ as $f$ increases, by calculating $\mathrm{d}\left[\log \left(W R_{A}\right)-\log \left(W R_{B}\right)\right] / \mathrm{d} f$. For simplification we assume that the developed economy adopts all new technologies, i.e. $d_{A}=1$. We get:

$$
\frac{\mathrm{d} \log W R_{A}}{\mathrm{~d} f}>\frac{\mathrm{d} \log W R_{B}}{\mathrm{~d} f} \text { iff } \quad d_{B}<1-\frac{m}{1-m} \frac{1-f}{f^{2}} .
$$

Hence, the effect of technical progress on the less developed country is smaller if it is significantly less developed. Note, that the higher the degree of technical progress $f$, the more likely it is that the effect on the less developed country is smaller, both due to the increase in $f$ and due to the decline in $d_{B}$.

Technical progress also affects the pattern of international trade. As shown above, an increase in $f$ increases both $d_{A} f$ and $d_{B} f$ as it increases the wage ratio in 
both countries. As can be seen from equation (25) an increase in $f$ raises the right hand side and as a result it reduces $k$. Hence, technical progress reduces the range of products exported from developed to less developed countries. Furthermore, we can examine how technical progress affects the share of trade in both countries. From equation (21) it follows that the share of trade in country $\mathrm{A}$ is equal to $m(1-k f)$, while in country $\mathrm{B}$ it is equal to $m k f$. Hence, whether technical progress increases $k f$ or not, the share of trade in one of the countries, either in $\mathrm{A}$ or in $\mathrm{B}$, declines as a result of skill-biased technical change. Note that this result does not fit the stylized facts of the recent decades. We know from many sources, such as Maddison (1995) and others, that the share of trade increased both in developed and in less developed countries. This result therefore means, that the recent global increase in wage inequality cannot be explained only by skill-biased technical change.

We next turn to examine the effect of trade liberalization on wage inequality. Here the difference between the two countries is dramatic. An increase in $m$ shifts the $W R_{A}$ curve upwards in Figure 3 and thus reduces $d_{A}$ and increases the wage ratio. Namely, trade liberalization increases wage inequality in the developed country, since it increases global demand for skilled workers in this country. In the less developed country the effect is opposite. A rise in $m$ shifts the $W R_{B}$ downward and thus increases $d_{B}$ and reduces the wage ratio in $\mathrm{B}$. Hence, trade liberalization increases global demand for unskilled workers in less developed countries and it therefore reduces wage inequality in such countries. Hence, the recent rise in wage inequality cannot be accounted for by trade liberalization only, as we observe an increase in wage inequality in less developed countries as well, as shown in Berman, Bound and Machin (1998). Our model therefore implies that no single factor can account for the stylized facts of the last decades. Only a combined effect of both skill- 
biased technical progress and trade liberalization can fully account for the changes in wage inequality across the world and in the global trade patterns.

The above analysis of the effect of trade liberalization also shows, that such a liberalization leads to convergence of economies to one another. As shown above the increase in $m$ leads to lower $d_{A}$ in the developed country and to a higher $d_{B}$ in the less developed country. Hence, a trade liberalization leads to more technology adoption in the less developed country and to less technology adoption in the developed country, unless it is fully developed, i.e. $d_{A}=1$. Therefore, the two countries become closer to one another as a result of more international trade.

As shown above, both skilled-biased technical progress and trade liberalization increase wage inequality. We next use the model to quantitatively compare these two effects. We compare the elasticities of $W R_{A}$ with respect to $f$ and to $m$ and get that:

$$
\frac{\partial \log W R_{A}}{\partial \log f}=\frac{1}{m+d_{A} f(1-m)} \frac{d_{A} f}{1-d_{A} f},
$$

and

$$
\frac{\partial \log W R_{A}}{\partial \log m}=\frac{1}{m+d_{A} f(1-m)} \frac{m}{1-m} .
$$

Hence, the effect of technical progress is larger than the effect of trade liberalization if and only if

$$
d_{A} f>m \text {. }
$$

This condition is satisfied if country A is fully developed, i.e. if $d_{A}=1$, and if $f>m$, namely if trade liberalization occurs when trade is quite limited and $m$ is rather small. From equations (31) and (32) we learn also that the wage ratio is highly sensitive both to technical progress and to trade liberalization as the above elasticities are quite high. 
If $d_{A}$ is equal to 1 and if $f$ is higher than $1 / 2$, then the elasticity of $W R_{A}$ with respect to $f$ is higher than 1 . A similar result holds with respect to $m$.

We now turn to examine the effects of technical progress and of trade liberalization if the equilibrium is not characterized by full specialization. We show that the results are similar to those under full specialization. Consider first the effect of an increase in $f$ on the equilibrium in the two countries. Since the equilibrium in country A is the same as in full specialization, and is given by conditions (7) and (23), the effect of technical progress is the same. Hence, as $f$ increases, $d_{A}$ decreases, the wage ratio increases, and $d_{A} f$ increases as well. Next examine equation (27), which describes the determination of $d_{B}$. An increase in $f$ increases (27) and hence it reduces $d_{B}$ and increases the wage ratio in country $B$ as well.

Consider next the effect of technical progress on the patterns of international trade. The share of trade in output in country $\mathrm{A}$ is $m\left(1-d_{B} f\right)$, as can be seen from equation (26). Note, that we cannot tell whether $d_{B} f$ is increasing or decreasing. We can also calculate the share of trade in output in country B and it is equal to:

$$
\frac{d_{B} f\left(1-d_{B} f\right)}{\frac{S_{B}}{S_{A}}\left(1+d_{A} f \frac{m}{1-m}\right)+1-d_{B} f} .
$$

It can be shown that the above share of trade is an increasing function of $d_{B} f$ as long as $d_{B} f<0.5$, which is a reasonable assumption. Hence, whatever the change in $d_{B} f$, whether it increases or declines, the share of trade in one country increases while in the other country it declines. Hence, the model yields a similar result to that in full specialization. Hence, in this case as well, technical progress alone cannot account for the stylized facts of the recent decades. 
We next examine briefly the effect of trade liberalization on equilibrium when there is no full specialization. An increase in $m$ shifts (23) up and hence increases the wage ratio. Examination of equation (27) reveals that an increased $\mathrm{m}$ and reduced $\mathrm{d}_{\mathrm{A}}$ shift (27) down and thus increase $d_{B}$ and reduce the wage ratio in country $\mathrm{B}$. Hence, the effect of trade liberalization on the two economies is similar to that in full specialization. Hence, in this case as well trade liberalization alone cannot account for the stylized facts of the recent decades.

\section{Long-Run Implications}

Until this section we have assumed that the supplies of the two types of workers are given. As a result, the economy adjusts to every change in technology or in trade by a full adjustment of wages and prices. That is a reasonable assumption in the short-run, but we know that in the long-run changes in relative wages lead to quantity adjustments as well. A rise in the relative wage of skilled workers creates an incentive to acquire skills and become skilled. As a result the long-run effect of technology or trade on the wage ratio might be much smaller than the short-run effect, which is analyzed above. We next examine the long-run effect of technical progress and trade liberalization, by introducing flexibility in skill acquisition. For the sake of simplicity, and in order to focus on the long-run equilibrium, we assume that career decisions are so flexible, that the long-run equilibrium is reached instantaneously.

Consider an economy, where individuals live one period each in consecutive generations. There is no population growth and each generation consists of a continuum of size 1 . Individuals have utility from consumption and disutility from the effort of learning. An individual can either work as unskilled, or study and work as skilled worker. The utility of each individual in the economy is 


$$
U=\log c-\delta \log e
$$

where $c$ is consumption, $e>1$ measures effort, and $\delta$ is equal to 1 if the individual invests in human capital and to 0 if not. We assume that the effort needed to study and invest in skills differs across countries, as it embodies the difficulty of education and of skill acquisition, access to education and similar issues. We assume that individuals are free to choose between the two alternatives and as a result utility from the two careers must equal. Hence the wage ratio is

$$
W R_{j}=\frac{w_{s j}}{w_{n j}}=e_{j}
$$

in each country $j \in\{\mathrm{A}, \mathrm{B}\}$.The wage ratio reaches this level by a full adjustment of the supplies of skilled and unskilled workers.

Note, that if the education system has some frictions, and the amount of individuals who acquire skills depends on the existing amount of skilled workers in the economy, condition (35) is not reached instantaneously, but after some time. Furthermore, the frictions in the education system can be such, that the economy might get stuck in a different equilibrium and never reach $(35){ }^{7}$ Our specification in this Section is, therefore, intended to present the steady state in an economy without traps, and we do it by ignoring the short-run dynamics and assuming that the economy moves to the steady state instantaneously.

\section{[Insert Figure 4 here]}

The equilibrium in each economy is presented in Figure 4, where the wage ratio is not determined by demand for the two types of labor, as in the former sections, but by the labor supply condition (35). The equilibrium wage ratio determines the

\footnotetext{
${ }^{7}$ This is the case for example if the capital markets are imperfect and individuals can finance education only by parental help, as in Galor and Zeira (1993).
} 
degree of technology adoption in each country $d_{j}$ and that determines the amounts of skilled and unskilled workers in each country according to equations (27) and (28) and to the constraint: $S_{j}=1-N_{j}$ in each country $j$. These variables also determine the variable $k$ and the pattern of international trade by equation (29).

Hence, in the long-run the wage ratio between skilled and unskilled workers is not affected by technical progress or by international trade, but by the access of individuals to education and skill acquisition, namely by the labor supply conditions. The more costly education is, namely the higher $e$ is, the higher the wage ratio in the country. Technical progress and international trade affect the amounts of workers of both types in the long-run, but not their relative wage. It can be shown that technical progress increases the amount of skilled workers in all countries, while trade liberalization increases the amount of skilled workers in the developed economy and reduces this amount in the less developed economy.

\section{Conclusions}

This paper constructs a theoretical model of skill-biased technical progress and of international trade in order to examine how the two processes together affect wage inequality in developed and less developed countries. The results of the model can shed some light on the recent debates on what has caused the rise in wage inequality in the US and in other western economies. Our model shows that the widening of the wage gap between skilled and unskilled workers cannot be attributed to one single factor, neither to trade liberalization nor to skill-biased technical progress.

According to the model trade liberalization increases the wage gap in developed countries, but reduces it in less developed countries. Since we observe in recent decades an increase in the wage gap in less developed countries as well, we 
conclude that it cannot be the result of trade liberalization only. We need to add the effect of skill-biased technical progress, which according to our model increases the wage gap both in developed and in less developed countries. But such technical progress cannot be the only factor that explains the rise in the wage gap for the following reason. Our model shows that skill-biased technical progress does not increase trade in all countries, and we know that in recent decades trade increased in all groups of countries. Hence, in order to account for the stylized facts of the recent decades, both technical progress and trade liberalization have to act together.

One important final comment is that all the changes discussed above in wage inequality are due to changes in demand for labor and are therefore short-run in nature. As time passes younger agents react to changes in wages by acquiring skills and thus wages gaps tend to be reduced. Hence, in the long-run the determinants of wage inequality are neither technology nor trade, but rather the ability of young people to acquire education and skills. Namely, in the long-run wage gaps are determined by the supply of labor rather than by the demand for labor. 


\section{References}

Acemoglu, Daron, "Why Do New Technologies Complement Skills? Directed Technical Change and Wage Inequality," Quarterly Journal of Economics, 113 (1998), 1055-1089.

Berman, Eli, John Bound, and Zvi Griliches, "Changes in the Demand for Skilled Labor whithin US Manufacturing: Evidencee from the Annual Survey of Manufacturers," Quarterly Journal of Economics, 109 (1994), 367-398.

Berman, Eli, John Bound, and Stephen Machine, "Implications of Skill-Biased Technological Change: International Evidence," Quarterly Journal of Ecomomics, 113 (1998), 1245-1279.

Bound, John, and George Johnson, “Changes in the Structure of Wages in the 1980's: An Evaluation of Alternative Explanations," American Economic Review, 82 (1992), 371-392.

Davis, Stephen J., "Cross-Country Patterns of Change in Relative Wages," in Olivier Blanchard and Stanley Fischer, eds., NBER Macroeconomic Annual 1992, MIT Press, Cambridge MA, 1992.

Davis, Stephen J., and John Haltwinger, "Wage Dispersion between and within US Manufacturing Plants, 1963-1986," Brookings Papers on Economic Activity: Microeconomics 1991,

Galor, Oded and Joseph Zeira, "Income Distribution and Macroeconomics," Review of Economic Studies, 60 (1993), 35-52.

Hanson, Gordon H., and Harrison Ann, “Trade, Technology and Wage Inequality," NBER Working Paper No. 5110, 1995.

Juhn, Chinhui, Kevin M. Murphy, and Brooks Pierce, "Wage Inequality and the Rise of Returns to Skill,” Journal of Political Economy, 101 (1993), 410-442. 
Katz, Laurence, and Kevin M. Murphy, "Changes in Relative Wages, 1963-1987:

Supply and Demand Factors," Quarterly Journal of Economics, 107 (1992), 35-78.

Leamer, Edward, "Wage Effects of a US-Mexico Free Trade Agreement," in Peter M. Garber, ed., The Mexico-US Trade Agreement, MIT Press, Cambridge MA, 1993.

Maddison, Angus, Monitoring the World Economy 1820-1992, OECD, Paris, 1995.

Wood, A., North-South Trade, Employment and Inequality, Clarendon Press, Oxford, 1994.

Zeira, Joseph, "Workers, Machines, and Economic Growth," Quarterly Journal of Economics, 113 (1998), 1091-1117. 
Figures

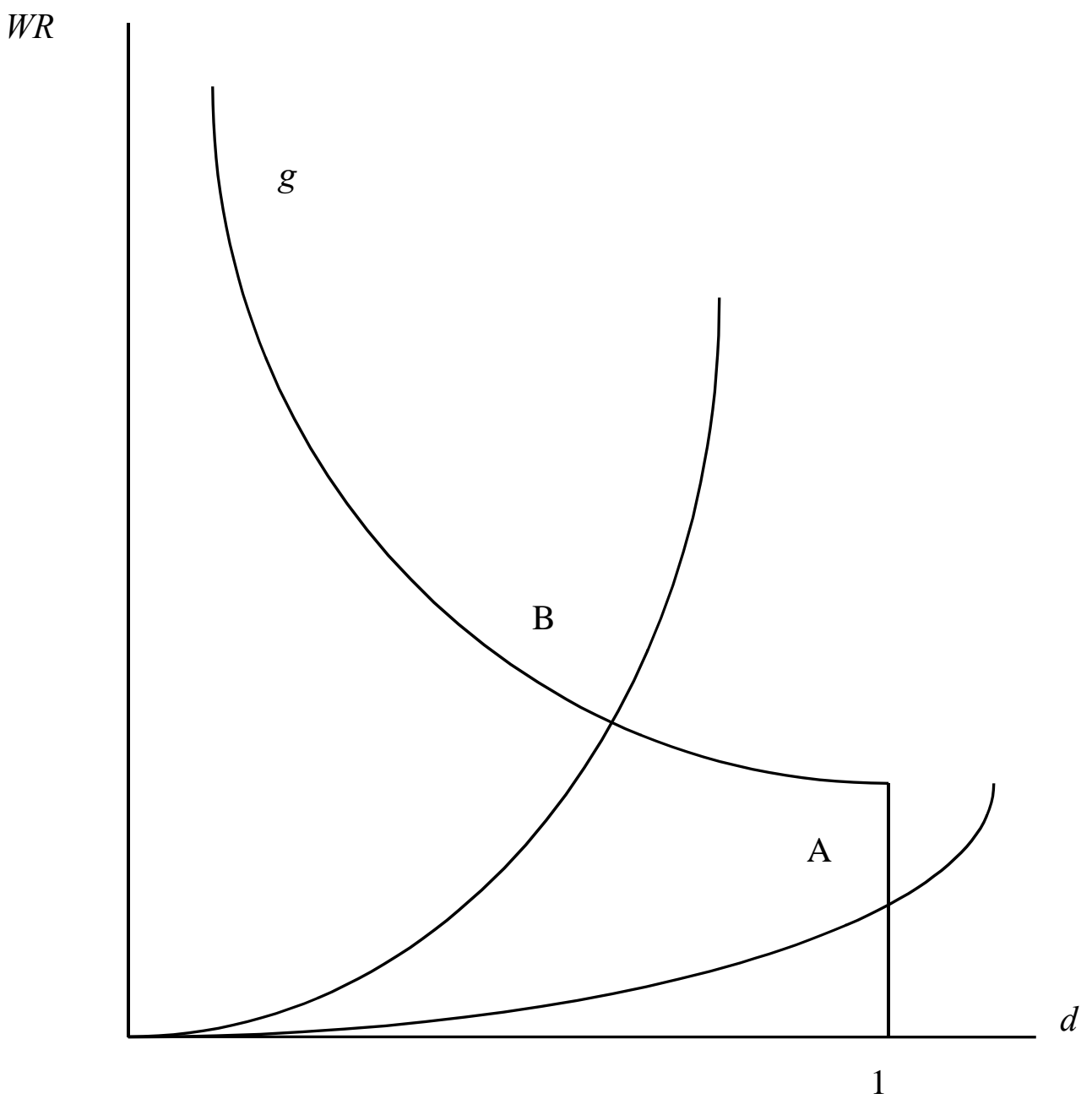

Figure 1 
A

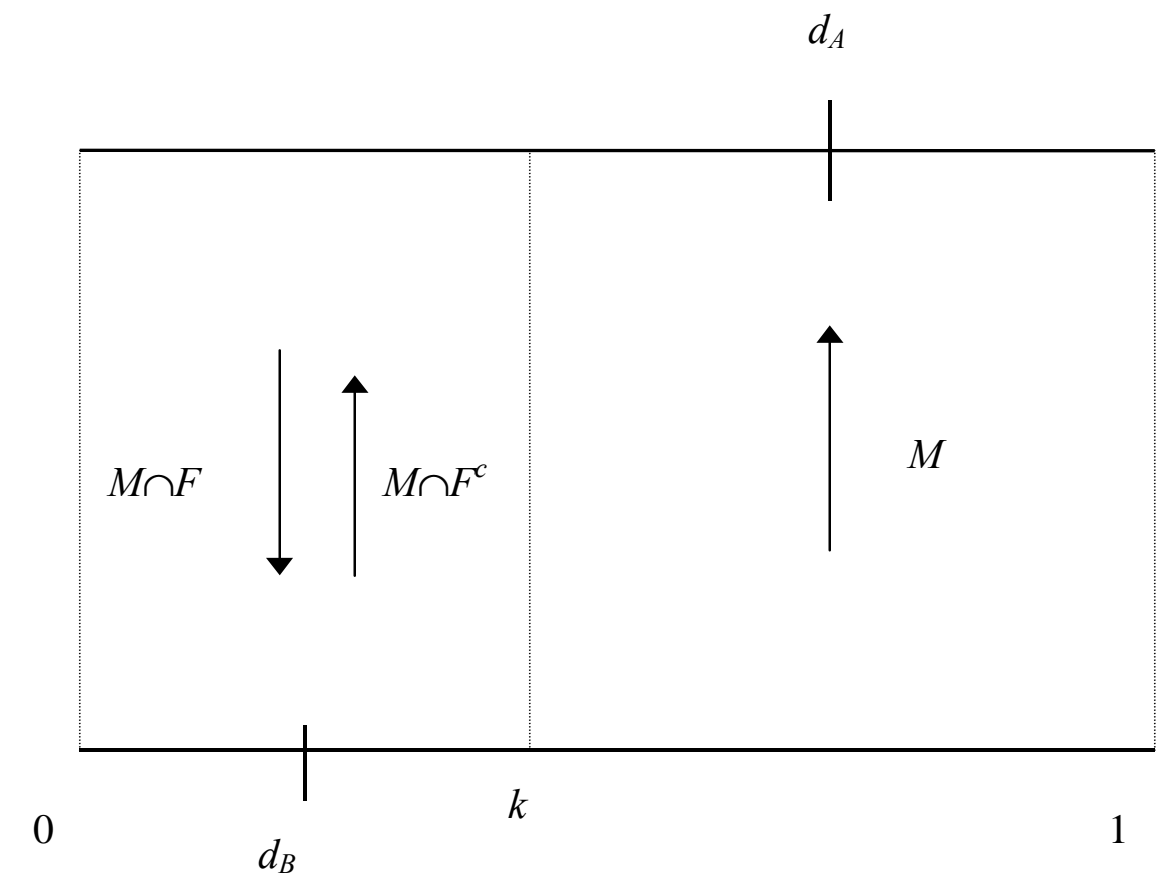

B

Figure 2 


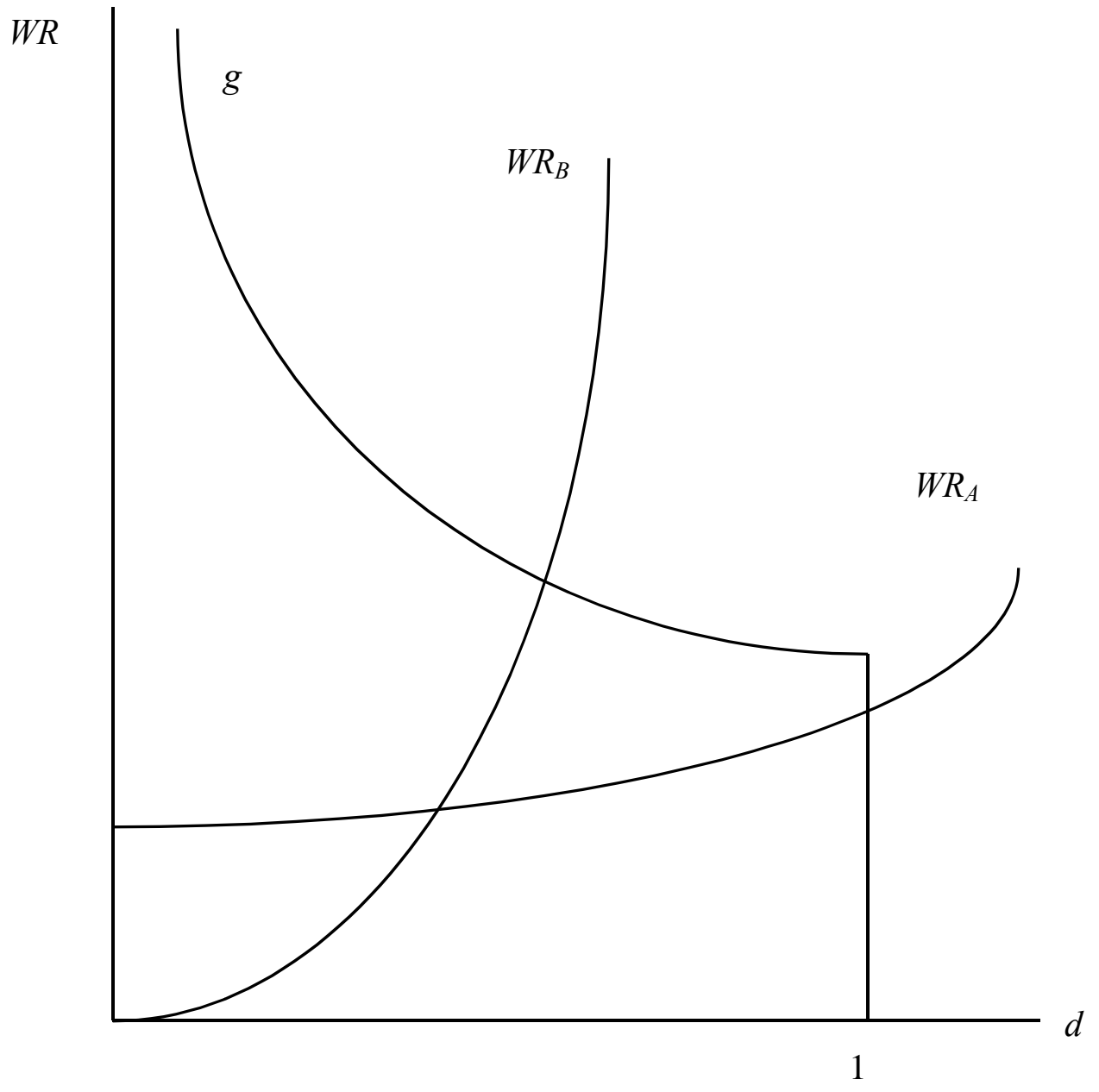

Figure 3 


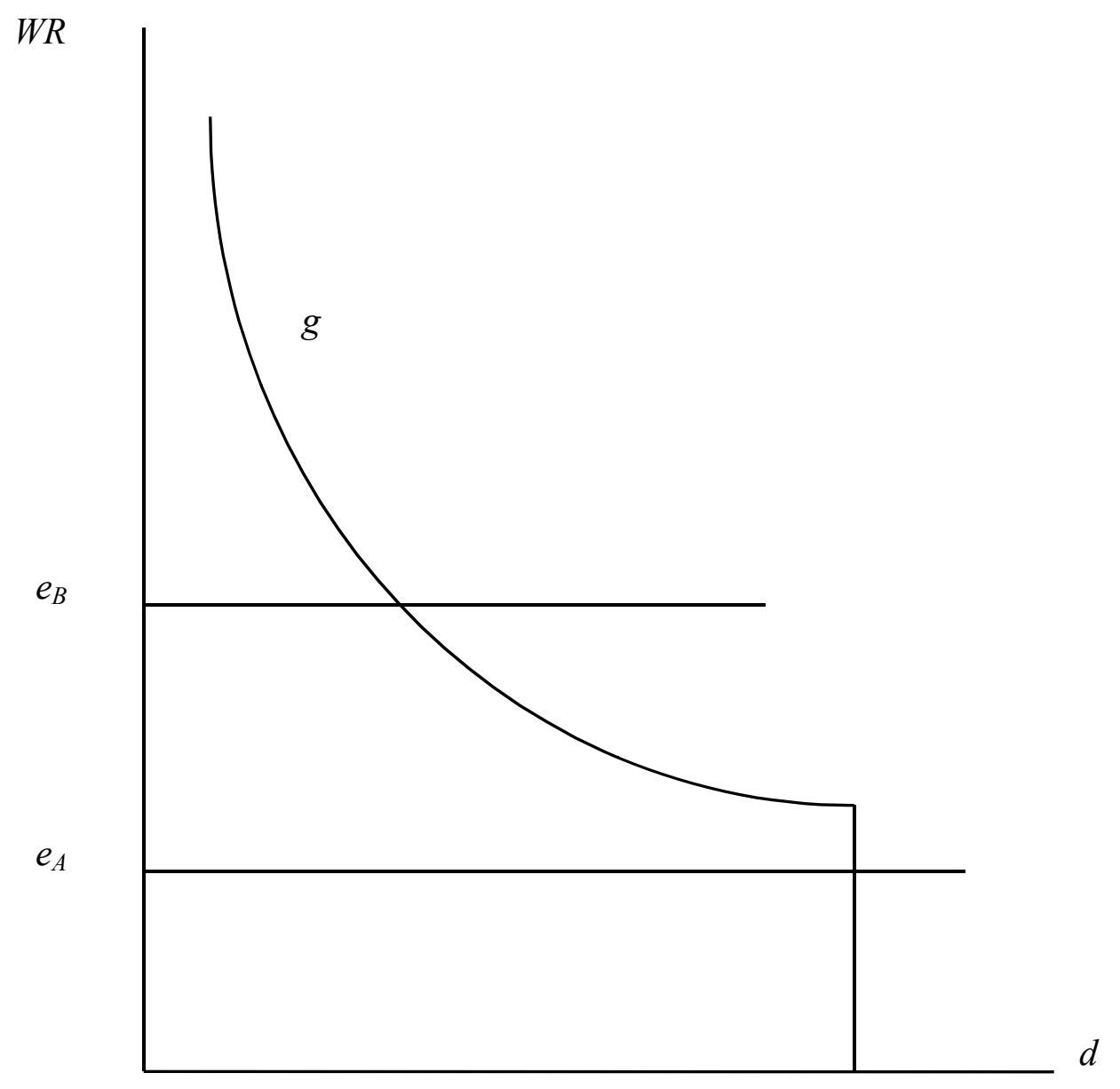

Figure 4 